\title{
Assessment on Female Students Achievement in Chemistry Subject at Merti Secondary School
}

\author{
Adane Gebre Silassie Hailemariam ${ }^{1}$, Girma Dadi ${ }^{2}$ \\ ${ }^{1}$ Chemistry Department, Dire Dawa University, Dire Dawa, Ethiopia \\ ${ }^{2}$ Chemistry Department, Merti High School, Merti Metehara, Ethiopia
}

Email address:

adanegebre19@yahoo.com (A. G. S. Hailemariam)

\section{To cite this article:}

Adane Gebre Silassie Hailemariam, Girma Dadi. Assessment on Female Students Achievement in Chemistry Subject at Merti Secondary School. Education Journal. Vol. 6, No. 6, 2017, pp. 200-206. doi: 10.11648/j.edu.20170606.16

Received: October 5, 2017; Accepted: October 20, 2017; Published: December 7, 2017

\begin{abstract}
The research was conducted in metehara merti high school. Research design for this study was survey research design. In Merti secondary school there are 45 students in grade 9 , using simple random sampling 18 female students and three chemistry teachers were selected. those the selected students were also based on their status low medium and high achivers. The data was collected through interview, questioner and from mark list. Majority of them (89\%) do not have their own study time. about $56 \%$ of respondents' responds cultural outlook affects their achievement. while about $78 \%$ of respondents responds burden at home is directly influence the achievement. The $83 \%$ of respondents' responds lack of confidence to learn chemistry subjects. About $78 \%$ of respondents responds that their teachers are not gave tutorial class and $72 \%$ respondent's responds that teachers do not implemented the classroom division. After the implementation of the action all those problems were solved.
\end{abstract}

Keywords: Metehara, Culture, Achiever, Students, Teacher

\section{Introduction}

\subsection{Back Ground of Study}

Chemistry is an important branch of science taught in the Senior Secondary Schools; it enables students to understand what happens in the world they live in and how it contributes to the quality of life on our planet (Ware, 2001). Chemistry curricula commonly incorporate many abstract concepts, which are central to further learning in both chemistry and other sciences (Taber, 2002). Chemistry topics are generally related to or based on the structure of matter, and proved to be a difficult subject for many students. [1]

Attitudes, like academic achievement, are important outcomes of science education in secondary school. The development of students' positive attitudes regarding science as a school subject is one of the major responsibilities of every science teacher. Unfortunately, research has revealed that much of what goes on in science classrooms is not particularly attractive to students across all ages. [2]

Across the globe, women comprise over $50 \%$ of the global population; however, they were marginalized in the economy; political and societal affairs. One of the major factors for such marginalization is society attitude towards Female education. It is adequately document that in traditional Ethiopia. The Orthodox Church\& the mosque were the major institution in change of dissemination education [1]. Ethiopia is established new education policy, which the objective of producing human power required for economic, social and technological development of the country [3].

Even if the final exam for grade 9th since 2008 E. C shows, when compares' female students with that of male students the points of male student are higher than female students, in Merti secondary school. Therefore, to alleviate the problem of Female students, the first and the most important steps should be taken by enhancing their education participation in all level of education. The purpose of this research is therefore, at least to high light idea which focused on the low achievement of female student in chemistry in Merti secondary school. [3]

This research is not an end by itself on female student's low achievement in chemistry but wished to be a stepping 
stone for other researchers who are eager to do detail as well as better study and come out with complete finding, therefore, the researcher is tried to explain the main ideas, which initiate to write this paper.

Females students have been achieved low result in chemistry relative to male students in the same class. The presence of problems of low achievement in chemistry has been conceived and grow and increasingly particularly since the last five months. Now it is the real time to make this problem naked out in a meaningful. Even though low achievement is common problem for other subject too, however, the researcher aimed to study with regard to the subject of chemistry.

The researcher conducted this research work to identify the main problem in the subject of chemistry in Merti secondary school. The presence of this problem has been supported also by the academic year since 2009 E. C chemistry mark list. By having the above mentioned problems of females low achievement in chemistry the writer hope that, through this research problems could be solved.

\subsection{Significance of the Study}

The research has been emphasized on the improving female students' achievement in chemistry subject in the case of Merti secondary school grade 9 students. The significance of this study is primarily to improve the achievements of female students.

Furthermore, researcher hopes that the study would help those who are interested in carry out large scale research on the area.

\subsection{Statement of the Problem}

The study of Chemistry is important in all aspects of life. Chemistry is a key subject for selective advancement in science and technology and needed for most careers in the education system. These careers include the health sciences (nursing, laboratory technicians, and doctors) and engineering. Conditions, which prevail in the education setup, however, discourage good performance of girls in science and by extension to chemistry [4]

In our country women constitute half of the population and large of labor force. From this perspective, the improvement of women participation in culture, socio- economic and political life of the country is more important, moreover, the importance of emphasizing on the participation of Female in education is considered necessary as one of millennium goal in 2015. [5, 16]

Nevertheless, the masked imbalance between the sexes in many fields of employment was not overcome completely. There are relatively few female scientists and engineers at the professional level and even fewer technicians and trades women at the skilled worker level [4]

Even after many attempts have been made to counter these factors, by governments as well as intervention by NGO's, lower achievement of female students still persists. This means that the real cause of lower achievement and poor performance in Chemistry have not been identified and therefore necessitating more research. It is in view of this gap, that the researcher felt that low achievement of female students in Chemistry subject needs further extensive investigation so as to bring about tangible improvements.

\subsection{Objective of the Study}

\subsubsection{Main Objective}

To improve female students' achievement in chemistry subject in the case of Merti secondary school grade 9 students.

\subsubsection{Specific Objective}

To assess the current performance female students in Merti secondary school.

To identify the factors that affects female students' achievement.

To provide a solution to the major challenge for female students achievement.

\subsection{Delimitation of the Study}

At this time there are many governmental schools in our country, but the researcher was focused only on Merti secondary School. In this school there are 350 grade 9 students section A-J. This research focuses only on grade nine students 'female who learn chemistry in Merti secondary school. Even though the issue raised in the research paper, has vast coverage due to time and financial constraints, the scope of the study is limited only to bind the eye view of the factor that affect female students.

\section{Review Literature}

The goal of education from its very nature is to being change in behavior female students to the part of the learner. The main emphasis of this research is female student's low achievement relatively to the male students. Education is a fundamental human right. However girls and women are defined this right according to united educational, scientific and culture organization (UNESCO). There are different educators who have been writing regarding to low achievement of females students. Of these educators findings the researchers was gathered some of the idea related to the topic under discussion. [15]

\subsection{Attitude of Female Students}

Attitude towards chemistry is essential; it denotes interests or feelings towards studying chemistry. Attitude and academic achievement are important outcomes of science education in secondary schools. Students' attitude and interest could play substantial role in students' decision to study science [5].

In the late 1980s there was a significant decline in chemistry education, and towards the turn of the century, the issue of attitudes towards an interest in chemistry became an international concern; recent publications presented a gloomy 
picture regarding students' ignorance in chemistry, and decline in enrollment in science-based careers. $[6,14]$

\subsection{Factor Affecting the Attitudes of Female Students Towards Chemistry}

According to the head school report 2005

Gender inequality in education is caused by a combination of many social - culture economic and political obstacles other related factors

Parent's excessive use of the girls' power.

The absence of role model woman in their surroundings.
The diversion of their attention by simple type of early marriage

Families under estimation of their daughters

Salta and Koulougliotis (2011) [7] identified the factors that could positively influence students' attitude to learn chemistry; these factors could be organized into three main categories:

Teaching approaches,

Educational tools,

Non-formal educational material and activities.

\subsection{Conceptual Framework}

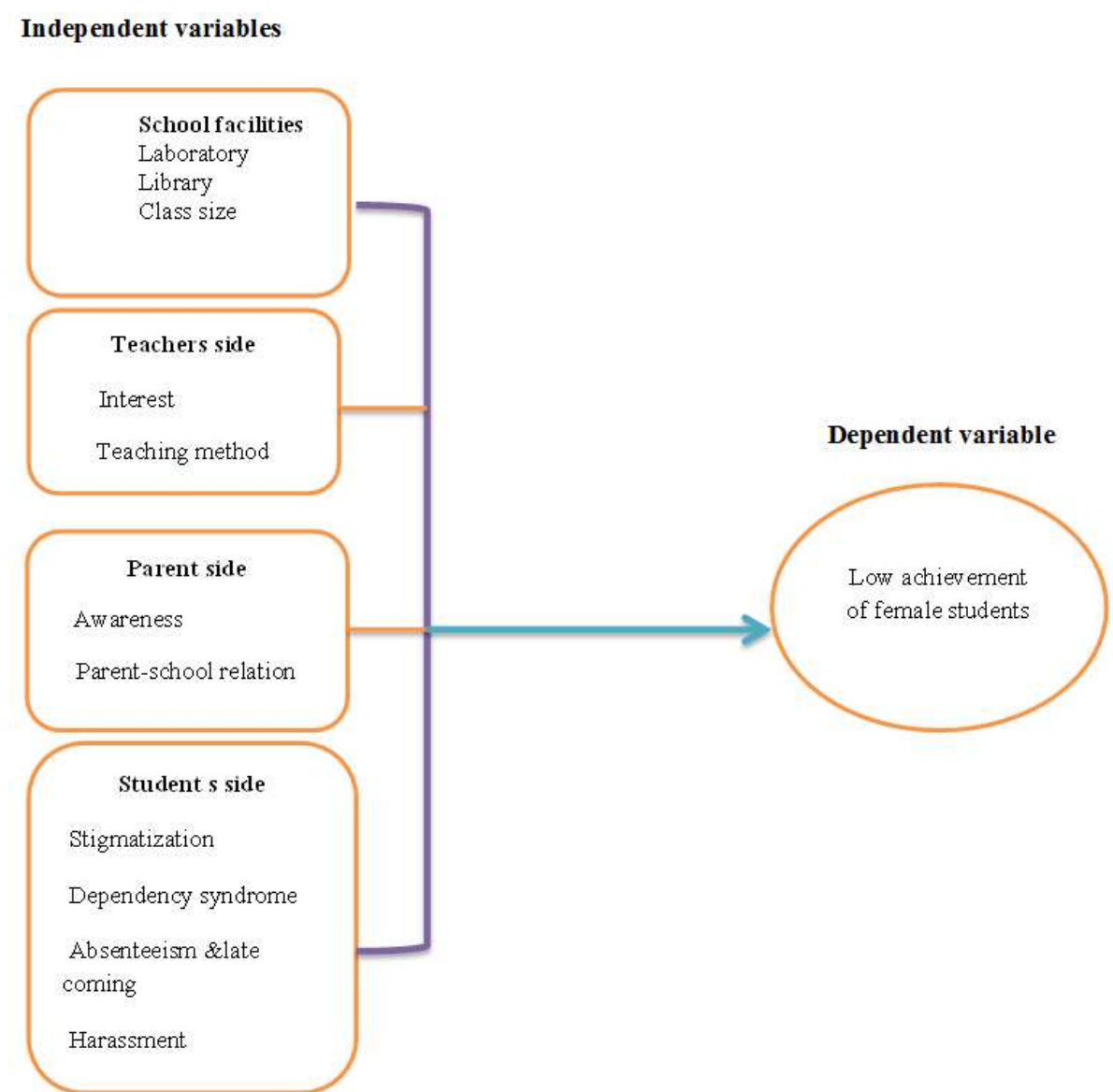

Source constructed by the researcher in 2008 .

Figure 1. Conceptual frame work.

\section{Research Methods}

\subsection{Description of the Study Area}

Merti secondary school is found in Fentale Woreda, East shoa zone, Oromia region at a distance of $199 \mathrm{~km}$ from the capital Addis Ababa, Ethiopia. It is the only high schools in the woreda found in the locality of Metahara sugar factory. The weather condition of this woreda ranges from 24.4 $38^{\circ} \mathrm{C}$. It is too hot. the population of Metahara is about 110,000 populations of whom $53 \%$ male and $47 \%$ are females. [12]

\subsection{Research Methodology}

\subsubsection{Research Design}

The nature of research design for this study was survey research design. Primary and secondary data were used for this study. Primary data was collected by using interview and questionnaire. Secondary data was collected from reliable published materials. For the survey, both probability and nonprobability sampling were processed, tabulated and further analyzed by using appropriate qualitative and quantitative techniques. [13] 


\subsubsection{Sample Size and Sampling Techniques}

The research conduct the population of 45 grade 9 female students in 2008 E. C of Merti secondary school, and the respectively three chemistry teachers. In Merti secondary school there are 45 students grade 9 section A- J out of these, using simple random sampling 18 female students were selected because small in numbers and only two chemistry teachers, in order to get full information knowledge about chemistry.

Table 1. Population and sample size.

\begin{tabular}{llll}
\hline No. & Status & Population size & Sample size \\
\hline 1 & High achievers & 5 & 3 \\
2 & Medium achievers & 9 & 5 \\
3 & low achievers & 20 & 10 \\
& Total & 34 & 18 \\
\hline
\end{tabular}

Source from Merti high school first semester result 2008

\subsubsection{Data Source and Data Collection Techniques}

The data for this study were collected from both primary and secondary data sources.

\section{i. Primary Data Sources}

Data collection instruments include questionnaires for female students and chemistry teachers in addition to the researcher by itself direct interaction with female students (class room observation).

\section{ii. Secondary Data Sources}

A secondary data source obtained from roster \& mark list of first semester and second semester.

\subsection{Data Analysis}

Twenty two copies of questionnaire were being distributed to 18 students \& two teachers. Once the data collection process completed, the data were organized, prepared to analyze. Quantitative data was analyzed by percentage and integrated with qualitative once.

\section{Data Analysis and Presentation}

This part of the research deals with the presentation and analysis of data collected respondents and class room observation of the researcher to address the fundamental research questions.

Data collected through the use of questionnaire were first categorized and depicted on various tables in the way that it could be understand easily, and statistical tools were used for analysis.

\subsection{Female Students' Response}

Table 2. Female students' response towards chemistry subject.

\begin{tabular}{llll}
\hline Item & Response & Frequency & Percentage \\
\hline \multirow{3}{*}{$\begin{array}{lll}\text { Do you have your own study } \\
\text { time? }\end{array}$} & Yes & 2 & 11 \\
& No & 16 & 89 \\
& Total & 18 & 100 \\
\hline
\end{tabular}

\begin{tabular}{llll}
\hline Item & Response & Frequency & Percentage \\
\hline $\begin{array}{l}\text { Do you think that cultural } \\
\text { outlook affect your }\end{array}$ & Yes & 10 & 55.56 \\
achievement? & No & 8 & 44.44 \\
Are female students & Total & 18 & 100 \\
burdened with house hold & Yes & 14 & 77.78 \\
cares that affect achievement & No & 4 & 22.22 \\
of chemistry subject? & Total & 18 & 100 \\
Are you participating in class & Yes & 1 & 5.56 \\
room teaching learning & No, & 17 & 94.44 \\
process? & Total & 18 & 100 \\
& Yes & 3 & 16.67 \\
How far are confident to & No & 15 & 83.33 \\
learn chemistry? & Total & 18 & 100 \\
\hline
\end{tabular}

Regarding the study time of the respondents, table 1, reveals majority of them $(89 \%)$ do not have their own study time while $11 \%$ have their own study time. It obvious that since the study area is located around Metehara sugar factory their families are either blue collar worker or white collar of the factory. Therefore all activities in the households are on the sholder of female students. This resulted no time to do assignments and study hard.

As table 1, item 2, reveals that it is about $56 \%$ of respondents' responds cultural outlook affects their achievement while $44 \%$ are disagree. In the study area female students come from different background of families, such as educated and illiterate. Illiterate families they preferred their daughters to married business man, Forman, supervisors and management bodies of factory workers instead of teaching female students. This is similar to the result of [8]. low parental socio-economic status is associated with diminished resources hence contributing to lower academic achievement

In the table 1 , item 3. Shows that it is about $78 \%$ of respondents responds burden at home is directly influence the achievement of female students in chemistry subject, while $12 \%$ responds burden at home is no influence on the achievement. In the study area house work is the only means to sustain life the female students. This resulted for female students coming to the school without looking their books and exercise books.

Regarding participation in the class room as the table 1 , item 4 , reveals that $94 \%$ are not participated while $6 \%$ are participated in class room during teaching and learning process. The major reason for lack of participation is of female students are they believed laugh by class mates, made faults, shine and etc. This finding is similar [9]. These factors hinder the participation of female students.

As table 1, item 5, reveals that it is about $83 \%$ of respondents' responds lack of confidence to learn chemistry subjects while the remaining $17 \%$ are confidence to learn the subjects. The reasons behind lack of interest's are they perceive the subject as difficult to understand and previously while they learn chemistry it is not supported by practical works like laboratory. This resulted to erode the confidence of female students towards chemistry subjects. This is similar 
to the findings of [10].

Table 3. Female students' response towards chemistry teachers.

\begin{tabular}{llll}
\hline Item & Response & Frequency & Percentage \\
\hline \multirow{2}{*}{$\begin{array}{l}\text { Does your chemistry } \\
\text { teacher treat you differently }\end{array}$} & Yes & 1 & 5.56 \\
& Total & 17 & 94.44 \\
How often your chemistry & Yes & 14 & 100 \\
teacher gives your tutorial & No & 4 & 78 \\
class & Total & 18 & 22 \\
Did the teacher divided the & Yes & 5 & 100 \\
class in to group and & No & 13 & 28 \\
encored female students to & Total & 18 & 72 \\
work in group? & & & 100 \\
\hline
\end{tabular}

As shown in the table 2 , item 1 , it is about $94.4 \%$ of respondents responds chemistry teacher does not treat differently female students while in teaching and learning process. And $5.56 \%$ of the respondents agree with the view that female students achieve low because of their burden with house hold cares.

In the table 2 , item 2 show that $78 \%$ of respondents responds that their teachers are not gave tutorial class while $22 \%$ agreed with the response of chemistry teachers provide tutorial class. It obvious that most of the time chemistry teachers could not provide tutorial class for female students rather than only intended focus to taught the regular class. This negatively affects the achievement of the female students.

Regarding division of the class and creating groups table 2 , item 3 reveals that it is about $72 \%$ respondents responds that teachers do not implemented the classroom division while in teaching and learning time. The remaining $28 \%$ agreed that teachers implement division in time of teaching and learning. It obvious that not only chemistry teachers but also other subject teachers did not followed divided students and creating group work, rather than preferring exclusive teaching in order to cover the portion. This resulted that female students not benefited from student centered learning.

\subsection{Chemistry Teachers Response}

Table 4. Response on where teachers give tutorial class and normal class for female Students differently.

\begin{tabular}{|c|c|c|c|}
\hline Item & Alternative & $\begin{array}{l}\text { No of } \\
\text { respondents }\end{array}$ & Percentage \\
\hline \multirow{3}{*}{$\begin{array}{l}\text { Do you agree tutorial } \\
\text { class for female student } \\
\text { beside the normal class? }\end{array}$} & Yes & 1 & 33.33 \\
\hline & No & 2 & 66.67 \\
\hline & Total & 3 & 100 \\
\hline \multirow{3}{*}{$\begin{array}{l}\text { Do you motivate female } \\
\text { students differently } \\
\text { while teaching } \\
\text { chemistry? }\end{array}$} & Yes & 2 & 66.67 \\
\hline & No & 1 & 33.33 \\
\hline & Total & 3 & 100 \\
\hline \multirow{3}{*}{$\begin{array}{l}\text { Do you divided the } \\
\text { class in to group and } \\
\text { encored female students } \\
\text { to work in group? }\end{array}$} & Yes & 0 & 0 \\
\hline & No & 3 & 100 \\
\hline & Total & 3 & 100 \\
\hline
\end{tabular}

According to the above table 3 , item 1 , it is about $66.67 \%$ of the respondent responds do not give tutorials class for female students besides the normal class while $33.33 \%$ of the respondents teachers gave tutorial class for female students in addition to the normal class. From the responses of the majority of respondents, it can be said that, do not gives tutorial class for female students beside the normal class, this result show that female students were not beneficiary from tutorial during teaching and learning process.

Regarding table 3, item 2, reveal that $66.67 \%$ of the respondent responds teachers motivated female students differently and other $33.33 \%$. of the respondents responds teachers do not solely motivate female students. In Merti secondary show that teachers were not involved in motivating students outside the class room such as gives award and etc.

As shown in table 3, item 3, it is about $100 \%$ of the respondent responds do not divide the class in to group and encourage female students to work in group. This means in other words female students do not got chance to learn chemistry in groups. This result hinders the performance of female students in Merti secondary school.

\subsection{Class Room Observation}

The researcher was also used another method of data collection. Through this observation, the researcher could identify some contributing of the most important factors to low achievement of female students in learning chemistry.

These are Female students are shine in class room as compare to male students. Chemistry teachers and also other subject teachers more attention gives to portion coverage instead of implementing different method of teaching and using laboratory. Female student's more abstain from the regular class as compared to male students.

Female students were absent and leave the class while they faced secondary sexual characteristics such as manustration. Number of students in the class room not invited and comfortable for teaching female students alone. Female students are not interested to participate in time of teaching and learning process.

\subsection{Research Findings}

Based on the collected data by using questionnaires and class room observation by the researcher the following problems are found out.

Female students were not getting enough tutorial class to improving their performance.

The teaching and learning process of chemistry teachers were not supported by the practical work or laboratory to in inculcate the lesson in the mind of students.

Female students were not encourage and were not grouped alone.

Female students were frequently absent and late coming to attend the regular class.

Parent of the students were lack of awareness about the tutorial program and its benefit on the female students achievement. 
Female students were victimized by inferiority complex in the class room as compared to male students.

At home female students were burden with household activities.

Table 5. Before action plan the achievements of female students in Merti Secondary School.

\begin{tabular}{lll}
\hline No & Status & Mean scored \\
\hline 1. & High achiever & 6.66 \\
2 & Medium achiever & 5.33 \\
3 & Low achiever & 3.55 \\
\hline
\end{tabular}

Source researcher mark list in 2008 first semester

\subsection{Action Plan Implementation}

Based on the action plan the following strategies were undertaken by the researcher;-

Provide extensive tutorial class for the female students by the researcher and incorporated with chemistry department.

After discussed with department of chemistry class room learning had been supported by practical works or laboratory.

Female students were encouraged/ motivated and created female group alone.

To reduce the rate of absenteeism and late coming discussed with female student

Made full awareness about the tutorial class schedule and benefit of the outcome for the parent of female students.

Arranged the program for female students by researcher and with the help civic and ethical education teacher in order to avoid the inferiority complex that was observed during teaching and learning interaction.

Researcher was discussed with the parent of female student about the duty at home and by this trend their future fate.

\subsection{Action Evaluation}

After the implemented the action plan by the researcher the following outcome were observed from the side of female students.

Female students were regularly attended both the regular class and tutorial class.

Female students were not merely know the lesson but also their knowledge have been supported by the practical work.

Female students were inspired both intra and inter group discussion.

Female students were not absent and late came by any means.

Inferiority complex is partially avoided from the side of female students.

Parent of the students show positive attitude for female students at home and tutorial class that was fixed by the teachers.

Over all the performance of the female students was improved.
Table 6. After action plan implemented the achievements of the students in Merti Secondary School.

\begin{tabular}{lllll}
\hline \multirow{2}{*}{ No } & \multirow{2}{*}{ Status } & \multicolumn{2}{l}{ Mean scored } & \\
\cline { 3 - 5 } & & Test one & Test two & Test three \\
\hline 1 & High achiever & 8 & 9 & 8 \\
2 & Medium achiever & 7.6 & 7.5 & 7.8 \\
3 & Low achiever & 5 & 6.5 & 6.8 \\
\hline
\end{tabular}

Source researcher mark list 2008 second semester

\section{Conclusion and Recommendation}

\subsection{Conclusion}

Studying about to improve the performance of the female students are a vital for the development avenue of the country. In this study, an attempt was made to assess some factors that hinder the achievement of female students in learning chemistry; the findings revealed that female students were immersed by different internal (school) and external (parents) factors. The internal factors (school) are the following;- lack of tutorial class, lack of using laboratory, teaching approach of the teachers and etc. while from the side of parents are low awareness about the tutorial class benefit for the female students in addition to high burden of female students at home

These findings, hopefully, will provide some useful information on how to improve female students' achievement toward chemistry subject. The present findings also provide insight information to the school science teachers and science curriculum planners to revise their teaching and learning methods, so that female students' achievements in chemistry eventually increase.

\subsection{Recommendation}

Improving the factors that affecting female student's achievement in chemistry subject in Merti secondary school was researcher prioritized problem. The above mentioned and related factors created a major problem in learning chemistry at Merti secondary school. However, this issue needs further and details study. Therefore, in order to improve and enhance the achievement of female students in learning chemistry at Merti secondary school. The following possible points are forwarded as recommendations.

Chemistry department should give extensive tutorial class to see consistently improve female students achievement. Chemistry teachers should stress on motivating students attitude by using the modern approach of teaching, using student center method. Chemistry teachers should treats \& encourage females' students in class room participation.

The administration of the school must organize in school and in supporting material. Parents should send their daughters to school on their appropriate time and treat them equally with their sons. The Worde educational bureau should collaborate with the women's affairs offices for collaborate effort against harm full traditional practices. 


\section{Appendix}

\section{Appendix A}

Questionnaires to Be Filled By students

Student back ground sex Age Female students' response.

Female students' response

1. Do you have your own study time?
A. Yes
B. No
2. What is your attitude towards chemistry subject?
A. Yes
B. No

3. Do you think your culture affect your achievement your study?
A. Yes
B. No.

4. Are Female students burdened with house hold cares that affect achievement of chemistry subject?

A. Yes B. No

5. Are you participate in class room teaching learning process?
A. Yes
B. No
6. How far are confident to learn chemistry?
A. Yes.
B. No

7. Does your chemistry teacher treat your differently?
A. Yes
B. No
8 . How often your chemistry teacher gives your tutorial class?
A. Yes.
B. No

\section{Appendix B}

Questionnaires to Be Filled By Teachers

Chemistry teachers Response

Teachers back ground sex Age

1. Do you agree tutorial class for female student beside the normal class?
A. Yes
B. No
2. Do you motivate female students differently while teaching chemistry?

A. Yes

B. No

3. Did the teacher divide the class in to group and encourage female student to work in group?
A. Yes
B. No

\section{References}

[1] Sirhan, Ghassan (2007): Learning Difficulties in Chemistry: An Overview, Journal of Turkish Sciences Education, Volume 4, Issue 2, pp 2-20.

[2] Stark, R., \& Gray, D. (1999). Gender preferences in learning science. International Journal of Science Education.

[3] Federal Democratic Republic of Ethiopia, 2002.

[4] Ware, S. A. (2001). Teaching chemistry from societal perspective, Pure and Applied Chemistry, 73(7), 1209-1214,

[5] Abulude, Olawale, (2009): Students' Attitudes towards Chemistry in Some Selected Secondary Schools In Akure Southlocal Government Area, Ondo State, unpublished dissertation, Affiliate of the Usman Dan Fodio University Sokoto.

[6] Hofstein, Avi and Naaman, Rachel (2011): High-School Students' Attitudes toward and Interest in Learning Chemistry, Universidad Nacional Autónoma de México, ISSNE 1870-8404.

[7] Salta, Katerina and Koulougliotis, Dionysios (2011): Students' Motivation to Learn Chemistry: The Greek Case.

Technological Educational Institute (TEI) of Ionian Islands (Greece).

[8] Costello, J. (1991). Teaching and Learning Mathematics. London: Routlodge, Chapman.

[9] Colley. (2002). Educational and training policy of Ethiopia. Addis Ababa.

[10] Eshiwani, G. S (1993) Mathematics education in Kenya since independence. East African Publishers, Nairobi.

[11] Durojaiye, M. O. A. (1976), A new Introduction to Educational Psychology. Nairobi: Evans Brothers Publishers.

[12] Fentale Woreda Agricultural Office, 2002.

[13] Karin Hyde, et al., (2005) Early marriage, abdication and rap rank high factor affecting the enrolment of girls school.

[14] Odage. A. and Henveled. J. (1995). Girls and school in Sahara Africa. World book. Washington DC.

[15] Taber, K. S., (2002). Alternative Conceptions In Chemistry: Prevention, Diagnosis.

[16] Twoli, N. W. (1986) Sex Differences in Science Achievement among secondary school students in Kenya. Flinders University, South Australia, Unpublished ph. D Thesis. 